\title{
Perbedaan Kesiapan Sekolah Anak Usia Dini di Daerah Pesisir ditinjau dari Status Ekonomi Orang Tua dan Parenting
}

\author{
Meyke Garzia ${ }^{1 凶}$, Yufiarti $^{2}$, Sofia Hartati ${ }^{3}$ \\ Pendidikan Anak Usia Dini, Universitas Negeri Jakarta
}

\begin{abstract}
Abstrak
Tujuan penelitian ini untuk menguji perbedaan status ekonomi orang tua dan child rearing (membesarkan anak) terhadap kesiapan sekolah anak usia dini di daerah pesisir Kecamatan Bantan Kabupaten Bengkalis Provinsi Riau. Penelitian ex post facto dengan desaim faktorial $2 \times 2$. Penentuan sampel menggunakan teknik purposive sampling berjumlah 100 orang tua. Penentuan sampel menggunakan rumus indeks kesukaran (rumus Johnson), dilanjutkan menentukan $27 \%$ responden yang menjadi kelompok Atas dan $27 \%$ menjadi kelompok Bawah (daya pembeda), sehingga diperoleh masing-masing sel menjadi 8 responden dengan total 32 orang tua. Pengumpulan data dilakukan melalui penyebaran kuesioner yang didesain dalam bentuk skala Likert. Analisis data menggunakan uji $F$. Penelitian memiliki lima hipotesis. Keseluruhan hipotesis menyimpulkan bahwa kesiapan sekolah dipengaruhi oleh status ekonomi orang tua dengan mempertimbangkan child rearing (membesarkan anak). Orang tua sebagai pendidik pertama dan utama diharapkan mengubah paradigma tentang bagaimana anak belajar dan memperoleh pengetahuan. Koordinasi dan komunikasi perlu terus dibangun dengan guru dalam upaya perbaikan kualitas pendidikan anak usia dini dalam mempersiapkan anak bersekolah.
\end{abstract}

Kata Kunci: daerah pesisir; kesiapan sekolah; anak usia dini

\begin{abstract}
The purpose of this study was to examine the differences in the economic status of parents and child rearing towards the readiness of early childhood schools in the coastal areas of Bantan District, Bengkalis Regency, Riau Province. Ex post facto study with 2x2 factorial design. Determination of samples using purposive sampling technique amounted to 100 parents. Determination of the sample using the difficulty index formula (Johnson formula), continued to determine $27 \%$ of respondents who became the Upper group and $27 \%$ to the Lower group (distinguishing power), so that each cell was obtained into 8 respondents with a total of 32 parents. Data collection is done through the distribution of questionnaires designed in the form of a Likert scale. Data analysis using F test. Research has five hypotheses. The overall hypothesis concludes that school readiness is influenced by the economic status of parents by considering child rearing. Parents as first and foremost educators are expected to change the paradigm of how children learn and acquire knowledge. Coordination and communication need to continue to be built with teachers in an effort to improve the quality of early childhood education in preparing children for school.
\end{abstract}

Keywords: child rearing; school readiness; early childhood

Copyright (c) 2019 Meyke Garzia, Yufiarti, Sofia Hartati

$\triangle$ Corresponding author :

Address : Jakarta, Indonesia

Email : meykegarzia@gmail.com

ISSN 2356-1327 (Media Cetak)

ISSN 2549-8959 (Media Online) 


\section{PENDAHULUAN}

Keberhasilan

belajar sangat ditentukan oleh tiga faktor yakni kesiapan pribadi anak itu sendiri, peran orang tua dan peran sekolah. Tujuan pendidikan adalah untuk mempersiapkan anak didik agar mampu beradaptasi dalam berbagai kondisi dengan baik sehingga anak mampu survive di masa akan datang. Literatur tentang kesiapan sekolah merupakan konstruk yang multifaceted yang mencakup kapasitas keluarga, kapasitas sekolah, lingkungan masyarakat dan kontribusi Pemerintah untuk mensupport perkembangan dan belajar anak (CFER, 2017). Berbagai studi menunjukkan manfaat dan pengembalian investasi dari kesiapan bersekolah, terkait dengan penurunan biaya pendidikan, peningkatan produktivitas dan pendapatan manusia, serta manfaat bagi masyarakat. Program-program pendidikan dan perkembangan anak usia dini yang efektif dapat menurunkan biaya pendidikan melalui peningkatan efisiensi internal pendidikan dasar dan sedikit anak mengulang kelas (UNICEF Bhutan, 2012).

Di Indonesia, telah dilaksanakannya program evaluasi tentang pendidikan anak usia dini berbasis masyarakat untuk meningkatkan akses pelayanan pendidikan anak dan meningkatkan kesiapan sekolah (Pradhan et al., 2013).

Beberapa laporan nasional dan internasional baru-baru ini, boomingnya "kesiapan sekolah" anak menjadi salah satu masalah paling mendesak di seluruh dunia terkait kebijakan pendidikan anak usia dini (National Association for the Education of Young Children, Standards, \& Curriculum, 2009). Dengan demikian, dalam mendukung upaya peningkatan kualitas pendidikan, maka diperlukan data yang valid dan reliable terkait kesiapan sekolah anak.
Di Eropa Barat issue kesiapan sekolah telah menjadi topik perdebatan dan kontroversi selama beberapa tahun terakhir. Hal ini dikarenakan penafsiran yang berbeda-beda terkait keterampilan anak yang dinilai agar berhasil memasuki masa sekolah, kualitas lembaga/sekolah, standar usia dan proses transisi yang dijalani anak dimulai dari rumah, prasekolah hingga memasuki Sekolah Dasar kelas awal (Sue Bingham and David Whitebread, 2018). Literatur lain menunjukkan anak-anak yang berusia 3 tahun aspek kesiapan nonakademis, seperti belajar disposisi dan kemampuan mengikuti peraturan kelas sama-sama penting bagi keberhasilan transisi mereka ke lingkungan prasekolah (Sha \& Li, 2019).

Statistik, (2016) menyebutkan keterlibatan anak pada pendidikan prasekolah mampu menentukan kesiapan anak untuk memasuki jenjang pendidikan dasar. Kesiapan tersebut meliputi lima aspek kompetensi, yaitu: kesehatan fisik dan perkembangan motorik, perkembangan sosial dan emosional, perkembangan bahasa, pendekatan untuk belajar, kognitif dan pengetahuan umum. Riset lain mengungkapkan bahwa ketidaksesuaian antara pemahaman orang tua dan guru tentang keterampilan kesiapan sekolah anak dapat mengakibatkan kesenjangan antara rumah dan lingkungan kelas. Oleh karena itu, perlunya intervensi lanjutan untuk mengubah perspektif antara orang tua dan guru melalui komunikasi yang terarah dan kuat (Litkowski \& Kruger, 2017).

Angka Kesiapan Sekolah (AKS) merupakan suatu indikator yang digunakan untuk melihat kesiapan anak dalam memasuki jenjang pendidikan dasar (SD/Sederajat). 


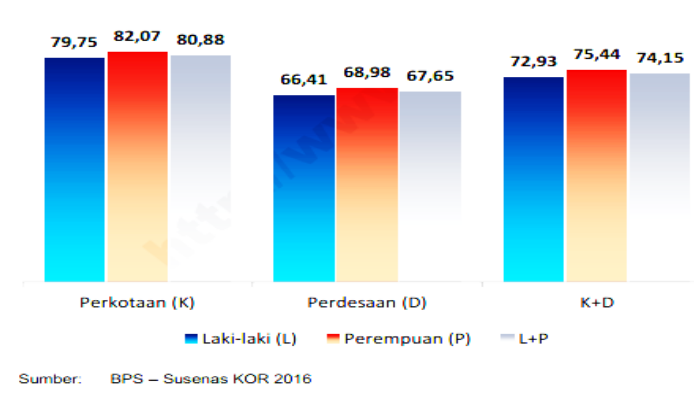

Gambar 1.1 Angka Kesiapan Sekolah (AKS) Anak Menurut Jenis Kelamin dan Daerah Tempat Tinggal, 2016

Kesiapan anak yang berasal dari keluarga yang berstatus ekonomi menengah bawah lebih rendah dibandingkan dengan anak yang berasal dari keluarga yang ekonomi menengah atas (Hartman, Winsler, \& Manfra, 2017). Anak dari keluarga berpenghasilan rendah tidak didukung lingkungan belajar yang kondusif dan anakanak terbiasa dengan lingkungan fisik dan sosial yang keras sehingga cenderung berdampak negatif dengan kemauan untuk belajar (Head \& Stanley, 2009). Adanya korelasi yang signifikan antara pendapatan keluarga dengan perkembangan otak anak usia dini (Frey, 2015). Ketidaksetaraan pertumbuhan global dan kemiskinan lintas dan di dalam negara mengingatkan bahwa kesiapan sekolah hanyalah satu bagian dari serangkaian masalah yang sangat besar dan kompleks (Bloch \& Kim, 2016).

Sikap membesarkan dan pemenuhan kebutuhan pendidikan anak merupakan aspek yang sangat penting bagi psikososial perkembangan anak. Penelitian Tocu (2014), menguji keyakinan dan sikap orang tua terhadap pengasuhan dan pendidikan, faktor yang mempengaruhi perkembangan anak.

Pemahaman kesiapan sekolah berhubungan positif dengan proses membesarkan anak dalam meningkatkan tumbuh kembang. Sedangkan transisi orangtua berhubungan positif dengan prestasi awal anak di TK (Puccioni, 2015).
Hasil penelitian lain menjelaskan hubungan orang tua dengan anak menjadi bantalan terhadap kesiapan psikososial dan sosioemosional anak-anak (Anderson, 2016). Hubungan hangat antara orang tua dan anak secara positif mempengaruhi kesiapan anak-anak untuk bersekolah, terutama bagi anak yang mengalami keterlambatan perkembangan (Simental et al., 2014). Dengan demikian, pentingnya konteks keluarga untuk kesiapan sekolah anak (Hughes, White, Foley, \& Devine, 2017). Salah satu prediktor paling akurat dari prestasi di sekolah tidak hanya pendapatan keluarga atau tingkat pendidikan orang tua, tetapi tingkat dimana orang tua percaya mereka bisa menjadi sumber penting dalam pendidikan anak mereka dan terlibat di sekolah dan masyarakat (Janice J. Beat, 2013)

Faktor keluarga dianggap yang memberi pengaruh besar dalam hal kesiapan sekolah anak (Syarfina, Elindra Yetti, 2018).

Beberapa fenomena terjadi dilapangan bahwa saat ini orang tua merasa penting untuk menyekolahkan anaknya, namun cenderung menuntut pada kemampuan akademik seperti calistung (membaca, menulis dan berhitung) tanpa memperhatikan aspek perkembangan berkaitan kemampuan dasar anak lainnya. Masih banyaknya orangtua merasa belajar disekolah masih kurang cukup terlebih orangtua menginginkan anaknya pintar dalam berhitung, mahir berbahasa inggris, dan sebagainya. Dengan kata lain, melalui les tambahan (bimbel) diharapkan anak memiliki kemampuan kognitif yang unggul, sejalan dengan tuntutan dan beban belajar disekolah dengan memaksimalkan kecakapan dan kemampuan kognisi.

Background yang berbeda dengan penelitian sebelumnya terkait demografi wilayah dan keadaan penduduk didaerah 
pesisir, unit analisis, jumlah sampel, indikator dan sebagainya maka menjadi penelitian ini belum pernah dilakukan. Ditinjau dari budaya membesarkan anak di daerah pesisir masih dominan mendendangkan shalawatan dan syair (gurindam dua belas) saat menidurkan anak, menstimulasi fisik motorik dan menggendong anak. Adanya program maghrib mengaji membuat anak-anak didaerah pesisir memiliki aktivitas rutin.

Di sisi lain, faktor ekonomi yang paspasan membuat orang tua lebih mementingkan mencari uang. Masyarakat pesisir yang mata pencahariannya adalah nelayan bergelut dengan laut untuk mendapat penghasilan, namun penghasilan yang diinginkan tidak bisa dikontrol. Karakteristik lain adalah ketergantungan pada musim. Ketergantungan pada musim ini akan semakin besar pada nelayan kecil. Pada musim penangkapan, para nelayan akan sibuk melaut. Sebaliknya, pada musim paceklik kegiatan melaut menjadi berkurang sehingga banyak nelayan yang terpaksa menganggur. Kaum perempuan (orang tua maupun anak-anak) seringkali bekerja sebagai pedagang ikan (pengecer), baik ikan segar maupun ikan olahan. Sementara itu, anak laki-laki seringkali dilibatkan dalam kegiatan melaut. Hal ini menyebabkan anak-anak nelayan banyak yang terlambat sekolah bahkan tidak sekolah.

Berdasarkan hasil observasi lapangan dilakukan ditemukan gejala dan fakta antara lain; (1) Pelaksanaan calistung di taman kanak-kanak sebagai bentuk kesiapan sekolah bagi anak, (2) tujuan kesiapan sekolah bagi anak menurut guru taman kanak-kanak dan orangtua memiliki perbedaan yang bermakna. Hal ini membuat guru taman kanak-kanak cenderung mengikuti kemauan orang tua yang menuntut anak bisa membaca, menulis dan berhitung dengan cara yang sedikit terkesan memaksa anak. (3) indikator kesiapan sekolah tidak hanya meliputi aspek perkembangan bahasa dan kognitif saja.

Berdasarkan latar belakang di atas, maka rumusan masalah dalam penelitian ini sebagai berikut: (1) Apakah terdapat pengaruh status ekonomi orang tua (tinggi dan rendah) terhadap kesiapan sekolah anak?, (2) Apakah terdapat pengaruh child rearing (positif dan negatif) terhadap kesiapan sekolah anak?, (3) sApakah terdapat pengaruh status ekonomi orang tua dan child rearing terhadap kesiapan sekolah anak?, (4) Apakah terdapat pengaruh perbedaan antara "status ekonomi orang tua tinggi dan child rearing positif" dengan "status ekonomi orang tua rendah dan child rearing positif" terhadap kesiapan sekolah anak?, (5) Apakah terdapat pengaruh perbedaan antara "status ekonomi orang tua tinggi dan child rearing negatif" dengan "status ekonomi orang tua rendah dan child rearing negatif” terhadap kesiapan sekolah anak?

Adapun tujuan penelitian adalah: (1) untuk mengetahui pengaruh status ekonomi orang tua (tinggi dan rendah) terhadap kesiapan sekolah anak; (2) untuk mengetahui pengaruh child rearing (positif dan negatif) terhadap kesiapan sekolah anak; (3) untuk mengetahui pengaruh status ekonomi orang tua dan child rearing terhadap kesiapan sekolah anak. (4) Untuk mengetahui pengaruh perbedaan antara "status ekonomi orang tua tinggi dan child rearing positif" dengan "status ekonomi orang tua rendah dan child rearing positif" terhadap kesiapan sekolah anak. (5) Untuk mengetahui pengaruh perbedaan antara "status ekonomi orang tua tinggi dan child rearing negatif" dengan "status ekonomi orang tua rendah dan child rearing negatif" terhadap kesiapan sekolah anak

Kesiapan sekolah melibatkan dua komponen utama yakni transisi dan kompetensi yang bersama-sama dalam 
mewujudkan proses kelancaran transisi dari lingkungan rumah untuk pengaturan terstruktur belajar (Britto \& Ulkuer, 2012). Kesiapan sekolah meliputi kesiapan untuk belajar didasarkan pada tingkat perkembangan fisik, kognitif dan sosial yang agar anak memenuhi tuntutan dan menjalani kurikulum yang telah ditentukan (Buysse, Wesley, Snyder, \& Pamela Winton, 2015). Selain itu, keterampilan yang dapat membantu anak untuk beradaptasi dengan tuntutan-tuntutan sekolah seperti sikap kerja yang baik, mampu berkonsentrasi, mampu mengelola ingatan, serta mampu membina relasi sosial (Peckham, 2017).

Semua hasil kesiapan sekolah anak diukur pada tahun anak pertama di TK (Johnson, Martin, \& Brooks-Gunn, 2013). Hojnoski and Missall menegaskan bahwa anak-anak usia sekolah awal yang mengalami kesulitan dalam belajar karena ketidaksiapan sekolah akan beresiko masuk ke dalam lingkaran masalah belajar, perilaku antisosial, dan menghindari lingkungan sekolah (Bruwer, Hartell, \& Steyn, 2014). Kesiapan sekolah secara umum dapat dibagi menjadi dua kategori utama, yakni pemahaman tentang proses perkembangan anak-anak dan pemahaman tentang kemampuan spesifik anak (Miller, 2019).

Membesarkan anak berhubungan positif dengan membaca dan matematika permulaan sehingga anak memiliki prestasi rata-rata lebih tinggi di TK sebagai persiapan menuju masa sekolah dasar (Puccioni, 2018). Kakia, Popov, \& Arani (2016), percaya bahwa tingkat komunikasi anak-anak dengan orang lain, interaksi dengan teman sebaya, tenang saat berpisah dari orangtua menjadi ukuran langsung kesiapan sekolah anak. Selain itu, program Kids in Transition to School (KITS) positif mempengaruhi keterampilan akademik dan regulasi diri anak yang merupakan salah satu indikator kesiapan anak untuk bersekolah dan meningkatkan konsistensi orang tua dalam penerapan pengasuhan serta keterlibatan disekolah (Pears, Carpenter, Kim, Peterson, \& Fisher, 2018).

Menurut Fayez, Ahmad, \& Oliemat, (2016) menyebutkan beberapa indikator kesiapan sekolah sebagai berikut antara lain: (1) keterampilan berkomunikasi, (2) disiplin diri, (3) keterampilan berfikir dasar, (4) pengetahuan akademik, perkembangan fisik motorik, dan (6) kematangan sosial emosional. Kesiapan sekolah anak tidak hanya tergantung pada pendewasaan saja namun perlu diperhatikan pula proporsi kematangan dan pembelajaran. Kematangan intelektual anak di evaluasi secara statistik diawal anak masuk sekolah (Review, 2016). Dengan harapan anak pergi ke sekolah, tinggal di sekolah, tumbuhnya perilaku positif dan mencapai keberhasilan akademik disekolah (Bloch \& Kim, 2016).

Teori Urie Bronfenbrenner yang menyatakan bahwa perkembangan anak termasuk kesiapan sekolah dipengaruhi lingkungannya. Untuk memahami anak dalam keluarga, harus melihat lingkungan keluarga yaitu atmosfer dan struktur atau komposisinya (Papalia, Old, \& Feldman, 2008). Orang tua yang terlibat dalam proses membesarkan anak yang bersekolah di TK akan mempererat hubungan dengan anak, mendapatkan tambahan pengetahuan dari TK ketika mengikuti kegiatan rutin dan dapat menerapkan ilmu pengetahuan baru yang dimiliki tersebut pada anak (Retnaningtya \& Paramitha, 2015). Dengan demikian, kesiapan sekolah merupakan kemampuan anak untuk belajar yang didasarkan pada kematangan aspek psikologis dan beradaptasi dengan tuntutan sekolah seperti keterampilan berkomunikasi, disiplin diri, keterampilan berfikir dasar, pengetahuan akademik, perkembangan fisik motorik, dan 
kematangan sosial emosional sehingga mampu menjalani proses pembelajaran di kelas.

Status ekonomi merupakan kemampuan ekonomi keluarga untuk memenuhi kebutuhan material dan non material. Pendapatan dan kepemilikan aset fisik sebagai penentu yang kesejahteraan status ekonomi orang tua (Yadollahi, Paim, \& Studies, 2010). Chuma dan Molynexu mengukur status ekonomi berdasarkan pengeluaran dan aset. Peneliti menetapkan bahwa status ekonomi rumah tangga dikategorikan di daerah pedesaan dan perkotaan (Chuma \& Molyneux, 2009). Status ekonomi keluarga juga dapat mengkategorikan menjadi dua tingkat yang pertama adalah 'tidak cukup untuk hidup dan yang kedua adalah 'cukup untuk hidup (Coton, Poly, Hoyois, Sophal, \& Dubois, 2008). Sedangkan penghasilan jangka panjang dianggap sebagai indikator utama keberhasilan ekonomi secara keseluruhan (Österbacka, 2017). Status ekonomi diklasifikasikan ke dalam kuartil pendapatan standar bulanan keluarga dengan skala kesetaraan penghasilan sama dengan rata-rata pendapatan keluarga bulanan/jumlah anggota keluarga (Koo, Kim, Yi, \& Moon, 2015). Dengan demikian, dapat disintesiskan bahwa status ekonomi adalah keadaan yang berkaitan dengan urusan pekerjaan, pendapatan orang tua, pemilikan kekayaan atau fasilitas, pendidikan, jenis tempat tinggal, dan jumlah anggota keluarga dalam memenuhi kebutuhan-kebutuhan sehingga mencapai kemakmuran dan kesejahteraan hidup.

Pepatah Afrika menyebutkan "Dibutuhkan sebuah desa untuk membesarkan seorang anak" berbicara tentang pentingnya peranan orang tua sangat memerlukan dukungan masyarakat yang kuat dalam membesarkan anak misalnya, memiliki rekan atau sahabat yang dapat diandalkan yakni memberikan dukungan moril dalam membesarkan anak (Sanders \& Turner, 2018)

Child rearing (membesarkan anak dengan cinta) merupakan membesarkan anak dengan menekankan pada pemberian kehangatan, pujian, dan kasih sayang ibu serta tanggap terhadap perilakuperilaku anak (Spera, 2015). (Yunus \& Dahlan, 2013)mengungkapkan definisi child rearing merupakan: In this study the term childrearing practices refers to the process of providing children with material needs, education, love, care and well-being so that they could grow and develop physically, socially, emotionally, intellectually and spiritually. Melalui keterlibatan yang setara dan aktif iniah, lingkungan yang aman, menyenangkan, dan merangsang bisa diciptakan bagi anak-anak. Orangtua untuk pertama kalinya dijelaskan sebagai yang mempunyai kompetensi tepat dan komitmen mendalam terhadap belajar anakanak akhirnya diakui (Beckley, 2018).

Dengan demikian child rearing merupakan perilaku orang tua dalam membesarkan anak yang meliputi pemenuhan kebutuhan dasar, ekspresi perilaku orang tua, nilai-nilai yang dianut, dan latihan perilaku yang meliputi conflict with child (konflik dengan anak), open communication (keterbukaan dalam komunikasi), warmth (kehangatan), protective/worries (perlindungan), anxiety induction (induksi kecemasan), independencelautonomy (kemandirian), dan discourges emotional expression (ekspresi emosi) untuk mendukung tumbuh kembang anak.

\section{METODOLOGI}

Penelitian ini dilakukan di daerah pesisir tepatnya kecamatan Bantan Kabupaten Bengkalis, Provinsi Riau. Pendekatan yang digunakan adalah kuantitatif dengan metode survei. 
Penentuan sampel menggunakan teknik purposive sampling berjumlah 100 orang tua. Menggunakan rumus indeks kesukaran yang mulanya dirintis oleh Johnson, kemudian perhitungannya diperbaiki oleh Flanangan, Guilford dan terakhir oleh Fan, dilanjutkan pembagian kelompok dengan mengurutkan perolehan skor total responden, lalu ditentukan $27 \%$ responden yang menjadi kelompok Atas dan 27\% menjadi kelompok Bawah (daya pembeda) sehingga diperoleh masing-masing sel menjadi 8 responden dengan total 32 orang tua. Pengumpulan data dalam penelitian ini dilakukan melalui penyebaran kuesioner yang didesain dalam bentuk skala Likert. Analisa data menggunakan uji $F$. Populasi dalam penelitian ini adalah orang tua yang memiliki anak bersiap untuk masuk Sekolah Dasar (SD) atau anak yang sedang menjalani pendidikan di TK Kelompok B yang ada didaerah pesisir.

Instrumen status ekonomi orang tua merujuk pada oktama (Oktama, 2013). Pengembangan instrumen kesiapan sekolah berdasarkan Standar Nasional Yordania yaitu sikap masyarakat dan orang tua terhadap kesiapan sekolah anak (CARES) dan Negara Arab telah memvalidasi sebagai Alat Evaluasi Awal Tahun (EYE). Instrumen ini bahkan telah digunakan secara universal (Fayez et al., 2016). Sedangkan instrumen child rearing berdasarkan New scales for the child rearing practices $Q$-short yang disusun oleh Roberts (2008) dimodifikasi berdasarkan Laporan Child Rearing (CRPR). CRPR berasal dari pengamatan empiris ibu yang berinteraksi dengan anakanaknya dalam berbagai situasi experimental terstruktur (Block, 1965). CRPR telah diterjemahkan ke dalam beberapa bahasa Norwegia, Swedia, Denmark, Finlandia, Kanton dan Belanda dan telah terbukti cocok sebagai instrumen yang digunakan untuk pengamatan lintas budaya. Kuesioner menggunakan Likert scale.

Pengujian validasi instrumen menggunakan Korelasi Pearson Product Moment.koefisien reliabilitas dihitung dengan formula Alpha Cronbach. Analisis yang digunakan adalah analisis deskriptif.

\section{HASIL DAN PEMBAHASAN}

Dalam pengujian normalitas menggunakan uji Lilifors dengan derajat bebas $(\mathrm{db})=\mathrm{n}$ (jumlah subjek ada 8 ) dan taraf nyata $\alpha=0.05$ diperoleh $\mathrm{L}_{\mathrm{t}}(0.05 ; 8)=$ 0.313. Kriteria pengujiannya adalah jika $\mathrm{H}_{0}$ diterima berarti sampel berdistribusi normal. Kriteria uji statistik yakni tolak $\mathrm{H}_{0}$ jika $\mathrm{L}_{0}>\mathrm{L}_{\mathrm{t}}$. Hasil perhitungan dan uji signifikansi normalitas secara keseluruhan terangkum dalam Tabel 4.1.

\begin{tabular}{ccccccc}
$\begin{array}{c}\text { Tabel 4.1 } \\
\text { dalam Uji Normalitas Data Skor Status } \\
\text { Ekonomi Orang Tua dan Child Rearing }\end{array}$ \\
\multicolumn{6}{c}{ Ringkasan Hasil Perhitungan } \\
(Membesarkan Anak) terhadap Kesiapan \\
Sekolah Anak Usia Dini
\end{tabular}

Berdasarkan Tabel 4.1 di atas, diperoleh nilai Lilifors hasil observasi $\left(\mathrm{L}_{0}\right)$ untuk seluruh kelompok data yang lebih kecil dari nilai $\mathrm{L}_{\mathrm{t}(0.05 ; 8)}$ (nilai kritis untuk uji Lilifors pada taraf nyata $\alpha=0.05$ dengan $n$ $=\mathrm{db}=8)$. Dengan demikian, dapat disimpulkan bahwa semua kelompok data dalam penelitian ini berasal dari populasi atau sampel yang berdistribusi normal. Oleh karena itu, syarat kenormalan data terpenuhi sehingga dapat digunakan dalam perhitungan hipotesis penelitian. 
Kriteria pengujiannya adalah terhadap keempat kelompok data tersebut diterimanya $\mathrm{H}_{0}$ jika $\mathrm{X}^{2}{ }_{\text {hitung }}$ lebih kecil dari $\mathrm{X}_{\text {tabel }}^{2}$ pada taraf nyata $\alpha=0,05$ dan $\mathrm{db}=3$ sebagaimana disajikan pada tabel di bawah

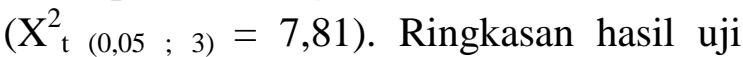
homogenitas varians melalui Uji Barlett

Tabel 2 Ringkasan Hasil Perhitungan dalam Uji Homogenitas Varians Kelompok Data Skor Status Ekonomi Orang Tua dan Child Rearing (Membesarkan Anak) terhadap Kesiapan Sekolah Anak Usia Dini

\begin{tabular}{ccccccc}
\hline No Urut & $\begin{array}{c}\text { Grou } \\
\mathrm{p}\end{array}$ & $\begin{array}{c}\mathrm{N} \\
\end{array}$ & $\begin{array}{c}\text { Varians } \\
\left(\mathrm{S}^{2}\right)\end{array}$ & $\begin{array}{c}\text { Nilai } \\
\mathrm{X}^{2}{ }_{\text {hitun }} \\
\mathrm{g}\end{array}$ & $\begin{array}{c}\text { Nilai } \\
\mathrm{X}_{\text {tabe }}^{2} \\
1\end{array}$ & Kesimpulan \\
\hline $\mathbf{1}$ & $\mathrm{A}_{1} \mathrm{~B}_{1}$ & 8 & 36,70 & $\mathbf{0 , 1 4 0}$ & $\mathbf{7 , 8 1}$ & Homogen \\
$\mathbf{2}$ & $\mathrm{A}_{1} \mathrm{~B}_{2}$ & 8 & 39,13 & & & \\
$\mathbf{3}$ & $\mathrm{A}_{2} \mathrm{~B}_{1}$ & 8 & 30,86 & & & \\
$\mathbf{4}$ & $\mathrm{A}_{2} \mathrm{~B}_{2}$ & 8 & 39,93 & & & \\
\hline
\end{tabular}

Berdasarkan Tabel 2 diketahui nilai nilai $\mathrm{X}^{2}{ }_{\text {hitung }}$ lebih kecil dari nilai $\mathrm{X}^{2}$ tabel sehingga keputusannya adalah $\mathrm{H}_{0}$ diterima. Hal ini berarti bahwa tidak adaperbedaan varians antara kelompok data yang diuji. Kesimpulannya bahwa keempat kelompok data kesiapan sekolah anak usia dini yang diuji berasal dari sampel yang variansinya bersifat homogen.

Data perhitungan skor kesiapan sekolah anak usia dini sampel penelitian untuk perhitungan ANAVA dua arah dideskripsikan dalam tabel 3 sebagai berikut:

\section{Tabel 3. Deskripsi Data Penelitian}

\begin{tabular}{|c|c|c|c|c|c|c|c|}
\hline \multirow{2}{*}{\multicolumn{2}{|c|}{$\begin{array}{c}\text { Kesiapan } \\
\text { Sekolah }\end{array}$}} & \multicolumn{4}{|c|}{ Status Ekonomi Orang Tua } & \multirow{2}{*}{\multicolumn{2}{|c|}{ Total }} \\
\hline & & \multicolumn{2}{|c|}{ (Tinggi) $\mathbf{A}_{1}$} & \multicolumn{2}{|c|}{ (Rendah) $\mathbf{A}_{2}$} & & \\
\hline \multirow{10}{*}{ 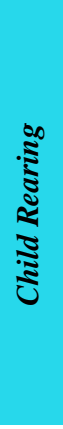 } & \multirow{5}{*}{ है } & $\mathrm{n}_{1}=$ & 8 & $\mathrm{n}_{2}=$ & 8 & $\mathrm{n}_{\mathrm{b} 1}=$ & 16 \\
\hline & & $\mathrm{SX}_{1}=$ & 801 & $\mathrm{SX}_{2}=$ & 620 & $\mathrm{SX}_{\mathrm{b} 1}=$ & 1421 \\
\hline & & $\mathrm{SX}_{1}^{2}=$ & 80457 & $\mathrm{SX}_{2}^{2}=$ & 48266 & $\mathrm{SX}_{\mathrm{b} 1}^{2}=$ & 128723 \\
\hline & & $\mathrm{x}_{1}=$ & 100,13 & $\mathrm{x}_{2}=$ & 77,50 & $\mathrm{x}_{\mathrm{b} 1}=$ & 88,81 \\
\hline & & $\left(\mathrm{SX}_{1}\right)^{2}=$ & 641601 & $\left(\mathrm{SX}_{1}\right)^{2}=$ & 384400 & $\left(\mathrm{SX}_{\mathrm{b} 1}\right)^{2}=$ & 2019241 \\
\hline & \multirow{5}{*}{ 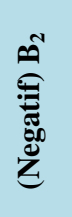 } & $\mathrm{n}_{3}=$ & 8 & $\mathrm{n}_{4}=$ & 8 & $\mathrm{n}_{\mathrm{b} 2}=$ & 16 \\
\hline & & $\mathrm{SX}_{3}=$ & 629 & $\mathrm{SX}_{4}=$ & 710 & $\mathrm{SX}_{\mathrm{b} 2}=$ & 1339 \\
\hline & & $\mathrm{SX}_{3}^{2}=$ & 49729 & $\mathrm{SX}_{4}^{2}=$ & 63292 & $\mathrm{SX}_{\mathrm{b} 2}^{2}=$ & 113021 \\
\hline & & $\mathrm{x}_{3}=$ & 78,63 & $\mathrm{x}_{4}=$ & 88,75 & $\mathrm{x}_{\mathrm{b} 2}=$ & 83,69 \\
\hline & & $\left(\mathrm{SX}_{3}\right)^{2}=$ & 395641 & $\left(\mathrm{SX}_{4}\right)^{2}=$ & 504100 & $\left(\mathrm{SX}_{\mathrm{b} 2}\right)^{2}=$ & 1792921 \\
\hline \multirow{5}{*}{\multicolumn{2}{|c|}{ 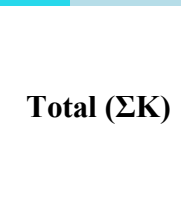 }} & $\mathrm{n}_{\mathrm{k} 1}=$ & 16 & $\mathrm{n}_{\mathrm{k} 2}=$ & 16 & $\mathrm{n}_{\mathrm{t}}=$ & 32 \\
\hline & & $\mathrm{SX}_{\mathrm{k} 1}=$ & 1430 & $\mathrm{SX}_{\mathrm{k} 2}=$ & 1330 & $\mathrm{SX}_{\mathrm{t}}=$ & 2760 \\
\hline & & $\mathrm{SX}_{\mathrm{k} 1}^{2}=$ & 130186 & $\mathrm{SX}_{\mathrm{k} 2}^{2}=$ & 111558 & $\mathrm{SX}_{\mathrm{t}}^{2}=$ & 241744 \\
\hline & & $\mathrm{x}_{\mathrm{k} 1}=$ & 89,38 & $\mathrm{x}_{\mathrm{k} 2}=$ & 83,13 & $x_{t}=$ & 86,250 \\
\hline & & $\left(\mathrm{SX}_{\mathrm{k} 1}\right)^{2}=$ & 2044900 & $\left(\mathrm{SX}_{\mathrm{k} 2}\right)^{2}=$ & 1768900 & $\left(\mathrm{SX}_{\mathrm{t}}\right)^{2}=$ & 7617600 \\
\hline
\end{tabular}


Tabel 4. Ringkasan Hasil Uji ANAVA Two Way

\begin{tabular}{|c|c|c|c|c|c|c|c|}
\hline \multirow{2}{*}{ Sumber Variansi } & \multirow{2}{*}{ Db } & \multirow{2}{*}{ JKA } & \multirow{2}{*}{$\begin{array}{c}\text { RJK = } \\
\text { JKA/db }\end{array}$} & \multirow{2}{*}{$\begin{array}{c}\mathbf{F}_{\text {hitung }}= \\
\text { R.JK/R.JK }\end{array}$} & \multicolumn{3}{|c|}{$\mathbf{F}_{\text {tabel }}$} \\
\hline & & & & & $\mathbf{0 , 0 5}$ & & \\
\hline $\begin{array}{c}\text { Antar Kolom (K) } \\
\text { (Status Ekonomi } \\
\text { Orang Tua) }\end{array}$ & 1 & 312,50 & 312,50 & 8,526 & $* *$ & 4,20 & 7,64 \\
\hline $\begin{array}{l}\text { Antar Baris (B) } \\
\text { (Child Rearing) }\end{array}$ & 1 & 210,13 & 210,13 & 5,733 & $*$ & 4,20 & 7,64 \\
\hline $\begin{array}{l}\text { Interaksi (B x K) } \\
\text { Antara Kelompok }\end{array}$ & 1 & 2145,13 & 2145,13 & 58,527 & $* *$ & 4,20 & 7,64 \\
\hline Dalam Kelompok (D) & 28 & 1026,25 & 36,65 & & & & \\
\hline Total Direduksi & 31 & 3694,00 & - & - & - & - & - \\
\hline
\end{tabular}

- $\quad$ = Signifikan $* *=$ Sangat Signifikan

Sebagaimana grafik interaksi dapat dilihat dibawah ini.

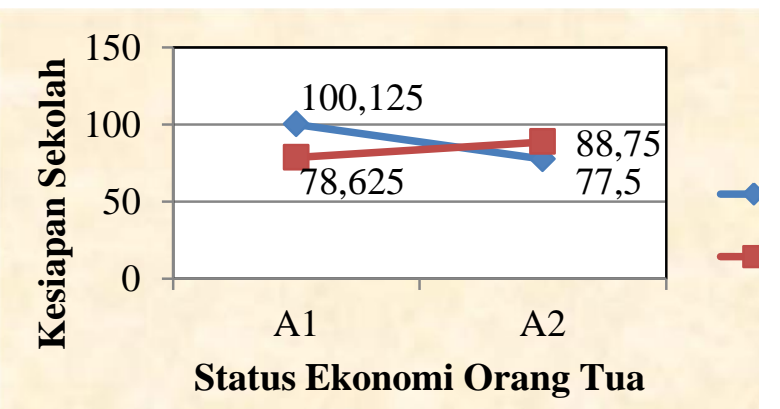

\section{Hipotesis 1}

Hasil pengujian hipotesis pertama, membuktikan bahwa secara keseluruhan terdapat perbedaan kesiapan sekolah anak usia dini yang status ekonomi orang tua tinggi daripada rerata skor kesiapan sekolah anak usia dini yang status ekonomi orang tua rendah.

\section{Hipotesis 2}

Berdasarkan hasil uji ANAVA dan uji perbandingan rerata skor kedua kelompok tersebut, dapat dikemukakan bahwa rerata skor child rearing positif $(88,81)$ lebih tinggi daripada rerata skor child rearing negatif $(83,69)$. Hasil pengujian hipotesis pertama, membuktikan bahwa secara keseluruhan terdapat perbedaan kesiapan sekolah anak usia dini yang child rearing positif lebih tinggi daripada rerata skor kesiapan sekolah anak usia dini yang child rearing negatif.

\section{Hipotesis 3}

Berdasarkan hasil pengujian hipotesis yang berkaitan dengan interaksi variabel status ekonomi orang tua dan child rearing diperoleh nilai $F_{\text {hitung }}$ lebih besar dari $F_{\text {tabel }}$ pada taraf signifikansi $\alpha=0,05$ ( $\mathrm{F}_{\text {hitung }}=$ $\left.58,527>\mathrm{F}_{\text {tabel }}=4,20\right)$. Hal ini berarti menolak hipotesis nol $\left(\mathrm{H}_{0}\right)$ dan menerima hipotesis kerja $\left(\mathrm{H}_{1}\right)$. Artinya, bahwa terdapat interaksi pengaruh yang signifikan antara status ekonomi orang tua dan child rearing terhadap kesiapan sekolah anak usia dini. Dengan demikian, dapat dikatakan bahwa kesiapan sekolah anak usia dini dipengaruhi secara signifikan dari interaksi antara status ekonomi orang tua dan child rearing.

Adapun rumus perhitungan sebagai berikut:

$Q=\frac{\mathrm{Xi}-\mathrm{Xj}}{\sqrt{\frac{\mathrm{RJKD}}{\mathrm{n}}}} \quad Q=\frac{100,13-77,50}{2,140}=$ 10,57 
Dari perhitungan diperoleh bahwa nilai $\mathrm{Q}_{\text {hitung }}=10,57 \geq \mathrm{Q}_{\text {tabel }(0,05)}=4,04$. Maka menolak $\mathrm{H}_{0}$ dan menerima $\mathrm{H}_{1}$ bahwa terdapat pengaruh interaksi yang signifikan antara status ekonomi orang tua (tinggi dan rendah) dan child rearing (positif dan negatif) terhadap kesiapan sekolah, sehingga diputuskan menolak $\mathrm{H}_{0}$ dan menerima $\mathrm{H}_{1}$.

\section{Hipotesis 4}

Dari hasil pengujian hipotesis yang berkaitan dengan status ekonomi orang tua tinggi diperoleh nilai $\mathrm{F}_{\text {hitung }}$ lebih besar dari $\mathrm{F}_{\text {tabel }}$ pada taraf signifikansi $\alpha=0,05\left(\mathrm{~F}_{\text {hitung }}\right.$ $\left.=8,526>\mathrm{F}_{\text {tabel }}=4,20\right)$.

Hasil perhitungan rerata skor kesiapan sekolah kelompok $\mathrm{A}_{1} \mathrm{~B}_{1}$ sebesar 100,13 lebih tinggi dari rerata skor kesiapan sekolah kelompok $\mathrm{A}_{2} \mathrm{~B}_{1}$ sebesar 77,50. Melalui uji Tukey pada taraf signifikansi $(\alpha$ $=0,05)$ diperoleh nilai $\mathrm{Q}_{\text {hitung }}=10,57 \geq$ $\mathrm{Q}_{\text {tabel }(0,05)}=4,04$, maka hipotesis nol $\left(\mathrm{H}_{0}\right)$ melalui uji $\mathrm{F}$ sejalan dengan hasil uji $\mathrm{Q}$ (angka Tukey).

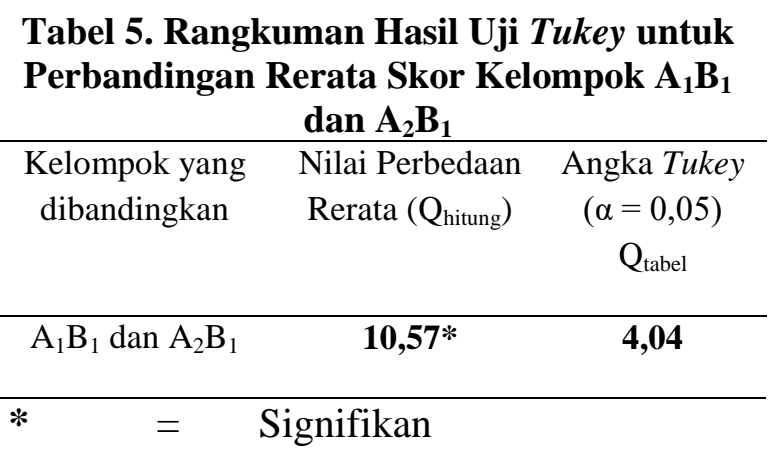

Berdasarkan hasil pengujian hipotesis keempat, menunjukkan bahwa secara keseluruhan kesiapan sekolah "status ekonomi orang tua tinggi dan child rearing positif" lebih baik daripada "status ekonomi orang tua rendah dan child rearing positif"

\section{Hipotesis 5}

Dari hasil uji $F$ diperoleh nilai $F_{\text {hitung }}$ lebih besar dari $\mathrm{F}_{\text {tabel }}$ pada taraf signifikansi $\alpha=0,05\left(\mathrm{~F}_{\text {hitung }}=5,733>\mathrm{F}_{\text {tabel }}=4,20\right)$ terhadap variabel kesiapan sekolah telah terbukti bahwa child rearing memberikan pengaruh yang signifikan terhadap kesiapan sekolah.

Melalui uji Tukey pada taraf signifikansi $(\alpha=0,05)$ diperoleh nilai $\mathrm{Q}_{\text {hitung }}$ $=4,73 \geq \mathrm{Q}_{\text {tabel }(0,05)}=4,04$ maka menolak $\mathrm{H}_{0}$ dan menerima $\mathrm{H}_{1}$. Hasil uji ini menggambarkan bahwa nilai kesiapan sekolah "status ekonomi orang tua tinggi dan child rearing negatif" lebih tinggi daripada "status ekonomi orang tua rendah dan child rearing negatif".

Rangkuman hasil uji Tukey kelompok ini dapat dilihat pada Tabel 4.16 dibawah ini.

Tabel 6. Rangkuman Hasil Uji Tukey untuk Perbandingan Rerata Skor Kelompok $A_{1} B_{1}$ dan $\mathbf{A}_{2} \mathbf{B}_{1}$

\begin{tabular}{ccc}
\hline $\begin{array}{c}\text { Kelompok yang } \\
\text { dibandingkan }\end{array}$ & $\begin{array}{c}\text { Nilai Perbedaan } \\
\text { Rerata }\left(\mathrm{Q}_{\text {hitung }}\right)\end{array}$ & $\begin{array}{c}\text { Angka Tukey } \\
(\alpha=0,05) \\
\mathrm{Q}_{\text {tabel }}\end{array}$ \\
\hline $\mathrm{A}_{1} \mathrm{~B}_{2}$ dan $\mathrm{A}_{2} \mathrm{~B}_{2}$ & $\mathbf{4 , 7 3 *}$ & $\mathbf{4 , 0 4}$ \\
\hline
\end{tabular}

Bagi orang tua yang mempunyai dukungan perekonomian mampu dan mapan memiliki banyak kemudahankemudahan dalam mendidik dan memenuhi kebutuhan anak-anaknya, sedangkan status ekonomi rendah dapat dikatakan status ekonomi tidak mampu (miskin) sehingga menyebabkan anak-anak bekerja membantu keluarganya di dalam mencukupi kebutuhan pada akhirnya banyak anak-anak putus sekolah (Oktama, 2013). Selanjutnya, korelasi yang signifikan antara pendapatan keluarga dengan perkembangan otak anak usia dini. Aspek perkembangan ini sangat penting agar anak siap menerima materi pembelajaran disekolah (Frey, 2015). Kesiapan anak yang berasal dari keluarga yang berstatus ekonomi menengah bawah lebih rendah dibandingkan dengan anak yang berasal dari keluarga yang ekonomi 
menengah atas (Hartman et al., 2017). Perbedaan yang signifikan antara status ekonomi orang tua tinggi dengan status ekonomi orang tua rendah terhadap kesiapan sekolah adalah terbukti.

Sedangkan hasil perhitungan rerata skor kesiapan sekolah anak usia dini yang child rearing positif (kelompok $\mathrm{B}_{1}$ ) sebesar 88,81 signifikan lebih tinggi dari rerata skor kesiapan sekolah yang child rearing negatif (kelompok $\mathrm{B}_{2}$ ) sebesar 83,69, maka hipotesis kerja $\left(\mathrm{H}_{1}\right)$ yang diterima. Hasil uji ini menggambarkan bahwa kesiapan sekolah anak usia dini yang child rearing positif lebih baik dibandingkan dengan kesiapan sekolah anak usia dini yang child rearing negatif. Sebagaimana dijelaskan oleh (Yunus \& Dahlan, 2013). Oleh karena itu, child rearing dan kualitas lingkungan rumah sangat penting dalam perkembangan kehidupan anak. Anak-anak dikelilingi dengan rasa cinta, dukungan dan motivasi. Membesarkan anak yang baik adalah melibatkan hubungan yang baik antara orangtua yang menyayangi anak, memfasilitasi sesuai dengan kebutuhan anak (Koby, 2012). Keyakinan dan sikap orang tua dalam membesarkan anak dan pemenuhan kebutuhan pendidikan mempengaruhi perkembangan anak (Tocu, 2014). Berdasarkan uraian yang telah dijelaskan di atas, maka disimpulkan bahwa terdapat perbedaan yang signifikan antara child rearing positif dengan child rearing negatif.

Dengan kata lain, terdapat pengaruh antara status ekonomi orang tua dan child rearing terhadap kesiapan sekolah pada taraf signifikansi $\alpha=0,05$. Hasil penelitian menunjukkan bahwa pemahaman kesiapan sekolah berhubungan positif dengan proses membesarkan anak dalam meningkatkan tumbuh kembang (Puccioni, 2015). Pendapatan keluarga meningkat memberikan peningkatan kualitas child rearing dirumah khususnya dikalangan keluarga dengan pendapatan terendah (Dearing \& Taylor, 2007). Selain itu, prestasi di sekolah tidak hanya pendapatan keluarga atau tingkat pendidikan orang tua, tetapi tingkat dimana orang tua percaya mereka bisa menjadi sumber penting dalam pendidikan anak mereka dan terlibat di sekolah dan masyarakat (Janice J. Beat, 2013). Berdasarkan pembahasan di atas, maka disimpulkan bahwa hasil penelitian ini relevan dengan penelitian yang telah ada. Pengaruh yang signifikan antara status ekonomi orang tua dan child rearing terhadap kesiapan sekolah adalah terbukti.

\section{KESIMPULAN}

Terdapat perbedaan data kesiapan sekolah antara status ekonomi orang tua tinggi dengan status ekonomi orang tua rendah. Terdapat perbedaan kesiapan sekolah anak usia dini yang child rearing positif dan negatif. Terdapat pengaruh yang signifikan antara status ekonomi orang tua dan child rearing terhadap kesiapan sekolah anak usia dini didaerah pesisir. Terdapat perbedaan status ekonomi orang tua tinggi dan child rearing positif" dengan "status ekonomi orang tua rendah dan child rearing positif terhadap kesiapan sekolah anak usia dini. Terdapat perbedaan "status ekonomi orang tua tinggi dan child rearing negatif" dengan "status ekonomi orang tua rendah dan child rearing negatif terhadap kesiapan sekolah anak usia dini” Orang tua sebagai pendidik pertama dan utama hendaknya mengubah paradigma tentang bagaimana anak belajar dan memperoleh pengetahuan. Koordinasi dan komunikasi perlu terus dibangun denagn guru dalam upaya perbaikan kualitas pendidikan anak usia dini. 


\section{UCAPAN TERIMA KASIH}

Peneliti mengucapkan terima kasih kepada orang tua di daerah pesisir Kecamatan Bantan kabupaten Bengkalis yang telah berpartisipasi dalam penelitian ini, serta pembimbing atas motivasi, saran, masukan serta umpan balik yang diberikan.

\section{DAFTAR PUSTAKA}

Anderson, R. E. (2016). Focusing on family: Parent - Child relationships and school readiness among economically impoverised Black children. The Journal of Negro Education, 84(3), 442-456. https://doi.org/10.7709/jnegroeducati on.84.3.0442

Beckley, P. (2018). Belajar pada Anak Usia Dini. Indonesia: Indeks.

Bloch, M. N., \& Kim, K. (2016). A Cultural History of "Readiness" in Early Childhood Care and Education: Are There Still Culturally Relevant, Ethical, and Imaginative Spaces for Learning Open for Young Children and Their Families? Rethinking Readiness in Early Childhood Education, 1-18. https://doi.org/10.1057/97811374851 20_1

Block, J. H. (1965). Child-rearing Practices Report. 1-37.

Britto, P. R., \& Ulkuer, N. (2012). Child development in developing countries: Child rights and policy implications. Child Development, 83(1), 92-103. https://doi.org/10.1111/j.14678624.2011.01672.x

Bruwer, M., Hartell, C., \& Steyn, M. (2014). Inclusive education and insufficient school readiness in Grade 1: Policy versus practice. 4(2), 1835 .

Buysse, V., Wesley, P., Snyder, P., \& Pamela Winton. (2015). EvidenceBased Practice: What Does It Really Mean for the Early Childhood Field? (pp. 2-11). pp. 2-11.

CFER. (2017). Menuju Sekolah Masa Depan Antara Harapan dan
Kenyataan (B. Nu'man \& L. Fridani, Eds.). Jakarta Pusat: Lentera Ilmu Cendekia.

Chuma, J., \& Molyneux, C. (2009). Estimating inequalities in ownership of insecticide treated nets: does the choice of socio-economic status measure matter? Health Policy and Planning, 24(2), 83-93.

Coton, X., Poly, S., Hoyois, P., Sophal, C., \& Dubois, V. (2008). The healthcareseeking behaviour of schizophrenic patients in Cambodia. International Journal of Social Psychiatry, 54(4), 328-337.

Dearing, E., \& Taylor, B. A. (2007). Home improvements: Within-family associations between income and the quality of children's home environments. Journal of Applied Developmental Psychology, 28(5-6), 427-444.

https://doi.org/10.1016/j.appdev.2007 .06 .008

Fayez, M., Ahmad, J. F., \& Oliemat, E. (2016). Jordanian Kindergarten and 1st-Grade Teachers' Beliefs About Child-Based Dimensions of School Readiness. Journal of Research in Childhood Education, 30(3), 293305.

https://doi.org/10.1080/02568543.201 6.1178195

Frey, S. (2015). Study of brain scans may show impact of poverty on academic achievement - EdSource. Edsource Highlighting Strategies For Student Success. Retrieved from https://edsource.org/2015/study-ofbrain-scans-shows-impact-of-povertyon-academic-achievement/84181

Hartman, S., Winsler, A., \& Manfra, L. (2017). Behavior Concerns Among Low-Income, Ethnically and Linguistically Diverse Children in Child Care: Importance for School Readiness and Kindergarten Achievement. Early Education and Development, 28(3), 255-273. https://doi.org/10.1080/10409289.201 6.1222121

Head, B. W., \& Stanley, F. J. (2009). The 
Australian Research Alliance for Children and Youth. Nova Publishers. Hughes, C., White, N., Foley, S., \& Devine, R. T. (2017). Family support and gains in school readiness: A longitudinal study. British Journal of Educational Psychology (C) 2017 The British Psychological Society, 16. https://doi.org/10.1111/bjep.12188

Janice J. Beat. (2013). Observing Development of the Young Child (8th Edition) 8th Edition (p. 384). p. 384. New York: Pearson; 8 edition.

Johnson, A. D., Martin, A., \& BrooksGunn, J. (2013). Child-care subsidies and school readiness in kindergarten. Child Development, 84(5), 18061822.

https://doi.org/10.1111/cdev.12073

Kakia, L., Popov, H. N., \& Arani, A. M. (2016). A study of relationships between parents' and teachers' demographic factors and their judgments about children's activities and school readiness in primary schools of Tehran. International Journal of Comparative Education and Development, 18(2), 100-119. https://doi.org/10.1108/ijced-102015-0006

Koby. (2012). What is Good Child Rearing_ Thinking about Child Care as a Child Issue - Honorary Director's Blog. Retrieved from Child Research Net website: https://www.childresearch.net/chief/4 8.html

Koo, B. K., Kim, S. W., Yi, K. H., \& Moon, M. K. (2015). Low Economic Status Is Identified as an Emerging Risk Factor for Diabetes Mellitus in Korean Men Aged 30 to 59 Years in Korean National Health and Nutrition Examination Survey 2008 to 2010. 137-146.

Litkowski, E., \& Kruger, A. C. (2017). Parents' and teachers' beliefs about school readiness: Working toward developing more culturally relevant interventions. International Public Health Journal, 9(2), 211-219. Retrieved from http://search.ebscohost.com/login.asp $\mathrm{x}$ ?direct=true \&AuthType $=\mathrm{ip}$, shib $\& \mathrm{db}$ $=\mathrm{jlh} \& \mathrm{AN}=124551681 \&$ site $=$ ehost live

Miller, S. A. (2019). Parents 'Beliefs about Children's Cognitive Development. 59(2), 259-285. Retrieved from https://www.jstor.org/stable/1130311 REFERENCES Linked references are av

National Association for the Education of Young Children, Standards, E. L., \& Curriculum, C. (2009). Developmentally Appropriate Practice in Early Childhood Programs Serving Children from Birth through Age 8. Young Children, 1-43. Retrieved from www.naeyc.org/files/naeyc/file/.../pos ition statement Web.pdf

Oktama, R. Z. (2013). Pengaruh kondisi sosial ekonomi terhadap tingkat pendidikan anak keluarga nelayan di Kelurahan Sugihwaras Kecamatan Pemalang Kabupaten Pemalang Tahun 2013. Universitas Negeri Semarang.

Österbacka, E. (2017). Family Background and Economic Status in Finland Published by: Wiley on behalf of The Scandinavian Journal of Economics Family Background and Economic Status in Finland. 103(3), 467-484.

Papalia, D. E., Old, S. W., \& Feldman, R. D. (2008). Human development (psikologi perkembangan). In Jakarta: kencana.

Pears, K. C., Carpenter, L., Kim, H. K., Peterson, E., \& Fisher, P. A. (2018). Kindergarten Transition and Readiness. Kindergarten Transition and Readiness, 283-302. https://doi.org/10.1007/978-3-31990200-5

Peckham, K. L. S. P. L. (2017). Developing school readiness: Creating life long learners. London.

Pradhan, M., Brinkman, S. A., Beatty, A., Maika, A., Satriawan, E., de Ree, J., \& Hasan, A. (2013). Evaluating a community-based early childhood education and development program 
in Indonesia: study protocol for a pragmatic cluster randomized controlled trial with supplementary matched control group. Trials, 14(1), 259.

Puccioni, J. (2015). Parents conceptions of school readiness, transition practices, and children's academic achievement trajectories. Journal of Educational Research, 108(2), 130-147. https://doi.org/10.1080/00220671.201 3.850399

Puccioni, J. (2018). Parental Beliefs About School Readiness, Home and SchoolBased Involvement, and Children's Academic Achievement. Journal of Research in Childhood Education, 32(4), 435-454. https://doi.org/10.1080/02568543.201 8.1494065

Retnaningtya, M. S., \& Paramitha, P. P. (2015). Keterlibatan orang tua dalam pendidikan anak di tk anak ceria. Jurnal Psikologi Pendidikan Dan Perkembangan, 4(1), 9-17.

Review, R. (2016). Taylor \& Francis, Ltd. 27(4), 361-378 https://doi.org/10.1080/07350190802 339259

Sanders, M. R., \& Turner, K. M. T. (2018). Handbook of Parenting and Child Development Across the Lifespan. Handbook of Parenting and Child Development Across the Lifespan. https://doi.org/10.1007/978-3-31994598-9

Sha, X., \& Li, H. (2019). Development and Validation of the Chinese Preschool Readiness Scale. Early Education and Development, O0(00), 1-18. https://doi.org/10.1080/10409289.201 9.1596462

Simental, J., Mastrianni, A., Green, J. G., Mintzer, C., Nicholas, W., Bates, M. P., \& Furlong, M. J. (2014). Bridging the Transition to Kindergarten: School Readiness Case Studies from California's First 5 Initiative. The California School Psychologist, 11(1), 41-56. https://doi.org/10.1007/bf03341114
Spera, C. (2015). A Review of the Relationship Among Parenting Practices, Parenting Styles, and Adolescent School Achievement Author ( $s$ ): Christopher Spera Published by: Springer JSTOR is a not-for-profit service that helps scholars, researchers, and students discov. 17(2), 125-146. https://doi.org/10.1007/s10648-0053950-1

Statistik, B. P. (2016). Potret Penddikan Indonesia Statistik Pendidikan 2016.

Sue Bingham and David Whitebread. (2018). School Readiness in Europe: Issues and Evidence. In International Handbook of Early Childhood Education (pp. 363-391). https://doi.org/10.1007/978-94-0240927-7

Syarfina, Elindra Yetti, L. F. (2018). Pemahaman Guru Prasekolah Raudhatul Athfal Tentang Kesiapan Sekolah Anak. Jurnal Pendidikan Usia Dini, 12(1), 153-163. https://doi.org/https://doi.org/10.2100 9/JPUD. 121.13

Tocu, R. (2014). Study on the Parental Beliefs and Attitudes towards Child Rearing and Education. Procedia Social and Behavioral Sciences, 137, 153-157. https://doi.org/10.1016/j.sbspro.2014. 05.268

UNICEF Bhutan. (2012). UNICEF Annual Report 2012: Bhutan. 1-33.

Yadollahi, M., Paim, L. H., \& Studies, C. (2010). Measurement of Family Economic Status 1 1. 6(11).

Yunus, K. R. M., \& Dahlan, N. A. (2013). Child-rearing Practices and Socioeconomic Status: Possible Implications for Children's Educational Outcomes. Procedia Social and Behavioral Sciences, 90(InCULT 2012), 251-259. https://doi.org/10.1016/j.sbspro.2013. 07.089 